\title{
THE GENUS THINOPHILUS WAHLBERG, 1844 (DIPTERA, DOLICHOPODIDAE) FROM EASTERN PALAEARCTIC, WITH DESCRIPTION OF TWO NEW SPECIES AND NEW RECORDS
}

\author{
Oleg P. Negrobov ${ }^{1}$, Olga O. Maslova ${ }^{2}$ and Olga V. Selivanova ${ }^{1}$ \\ ${ }^{1}$ Voronezh State University, Universitetskaya pl. 1, Voronezh 394006, Russia \\ E-mail: negrobov@list.ru \\ ${ }^{2}$ Voronezh State Pedagogical University, Lenina 86, Voronezh 394043, Russia \\ E-mail:oom777@yandex.ru
}

Two new species of the genus Thinophilus Wahlberg, 1844 are described: Thinophilus (Schoenophilus) grootaerti, sp. n. from the Maritime Territory and Thinophilus ovtshinnikovae, sp. n. from China. Subgenus Schoenophilus Mik, 1878 are recorded for the first time from Asia. Lectotypes and paralectotypes for Thinophilus pollinosus Loew, 1871 and Thinophilus seticoxis Becker, 1922 are designated. Thinophilus pollinosus Loew, 1871 are recorded for the first time from Russia. New data on the fauna of the genus Thinophilus of Russia and Mongolia are given. A new key to species of the genus Thinophilus from Eastern Palearctic region including 12 species is also presented.

Key words: Dolichopodidae, Thinophilus, Palaearctic, Maritime Territory, Mongolia.

\section{INTRODUCTION}

In the world more than 146 species of the genus Thinophilus Wahlberg, 1844 are known. In the Palaearctic region 23 species of this genus are described so far. The latest revision of the genus was published by Negroвov (1971), and the overview of the Palaearctic species of the genus was published by Negrobov (1979).

The number of species of the genus Thinophilus are known from the Asian part of the Palaearctic region, mostly from Central Asia: Thinophilus bicalcaratus Negrobov, 1971 - Turkmenistan, Uzbekistan, Tajikistan; T. brevicilius Negrobov, 1971 - Tajikistan, Uzbekistan, Kirghizia; T. vanschuytbroecki Negrobov, 1971 Azerbaijan, Turkmenistan, Afghanistan; T. ornatus Negrobov et Grichanov, 1982 and T. gissaricus Negrobov et Grichanov, 1982 are described from Tajikistan.

Four species were described from the eastern Palaearctic: Thinophilus longipilus Negrobov, 1971 from Maritime Territory of Russia and Japan (NEGrobov 1971, Negrobov et al. 2014), T. setosus Negrobov, 1979 from Mongolia and T. sinensis Yang et Li, 1998 from Palaearctic and Oriental parts of China, Thinophilus nigripennis Negrobov, Kumazawa et Tago, 2014 from Japan.

Four species were known from Mongolia: Thinophilus pollinosus Loew, 1871, T. argyropalpis Becker, 1907, T. flavipalpis (Zetterstedt, 1843) and T. ruficornis (Haliday, 1838) (Negrobov 1973, 1974). 
The subgenus Schoenophilus Mik, 1878 with typical species Schoenophilus versutus Haliday, 1851 are known from Central and South Europe and from North Africa. Several authors consider Schoenophilus as independent genus, and several researchers suppose that Schoenophilus is the subgenus of the genus Thinophilus.

Allocation of the genus Schoenophilus occurs by the presence of 4 pairs of dorsocentral setae, apical or subapical arista of males, in contradistinction to the genus Thinophilus, representatives of which is characterized by presence of 5-6 pairs of dorsocentral setae and dorsal arista (Negroвov 1971). Several species and subspecies of the genus Schoenophilus are described from Papua New Guinea and subantarctic islands of New Zealand: Thinophilus (Schoenophilus) pedestris (Lamb, 1909), T. (S.) pedestris campbellensis (Harrison, 1964), T. (S.) fuscicoxalis Grootaert et Meuffels, 1984, T. (S.) hilaris Parent, 1941, and T. (S.) splendens Grootaert et Meuffels, 1984 (Lamb 1909, Parent 1941, Harrison 1964, Grootaert \& Meuffels 1984).

Only one species from this genus are known from Palaearctic - Thinophilus (Schoenophilus) versutus, Haliday, 1851, description of which is available in the monograph of Negrobov (1979). Thinophilus (Schoenophilus) versutus Haliday, 1851, are known from England, Algeria, Belgium, Bulgaria, Denmark, France, Germany, Greece, Hungary, Ireland, Italy, Morocco, Netherlands, Poland, Romania, Russia, Sweden, Tunisia, Turkey, Ukraine.

\section{MATERIAL}

The study is based on the material from the funds of the Zoological Institute of the Russian Academy of Sciences and specimens from the collection of the Voronezh State University collected by O. P. Negrobov during the expedition in the Maritime Territory on the territory of the natural state reserve "Kedovaja Padj". The materials has been collected by Dr. Z. Kaszab from Hungarian Natural History Museum in Mongolia were also investigated. Types of Thinophilus pollinosus Loew and T. seticoxis Becker from the Zoological Museum of Humboldt University of Berlin are investigated.

\section{RESULTS}

\section{Thinophilus (Schoenophilus) grootaerti sp. n.}

(Figs 1-6)

Diagnosis. Frons with brown pollinosity. Clypeus with yellow-brown pollinosity. Antennae black. Pedicel without process, projecting on postpedicel. Arista apical. Mesonotum without black spot. 4 pairs of dorsocentral setae. Scutellum with 2 strong lateral setae. Legs yellow. Fore coxa with white hairs. 1st segments of fore tarsus not curved. Segments of tarsi not widened. 
Description. Male. Frons dull green with brown pollinosity. Clypeus with yellowbrown pollinosity. Epistome green with grey pollinosity. Antennae black. Postpedicel with long hairs, reniform, with oval apex, wider than long. Pedicel without process, projecting on postpedicel. Ratio of clypeus length, epistome length to face width at suture: $0.6 / 0.9 / 0.5$. Arista apical, shortly pubescent. Ratio of postpedicel length to width and arista length: 0.4/0.5/2.6. Proboscis dark-brown. Palpus yellow with black hairs. Postocular setae white below.

Thorax dark-green, with bronze tingle. Mesonotum with grey pollinisity, pleura with dense pollinosity. Mesonotum without black spot. Propleuron with white hairs. Acrostichal setae absent. 4 pairs of dorsocentral setae. Scutellum with 2 strong lateral setae.

Legs yellow excluding brown mid and hind coxa with yellow apex and yellow apex of tibia. Fore coxa with white hairs. Segments of tarsi not widened, without bunch of long
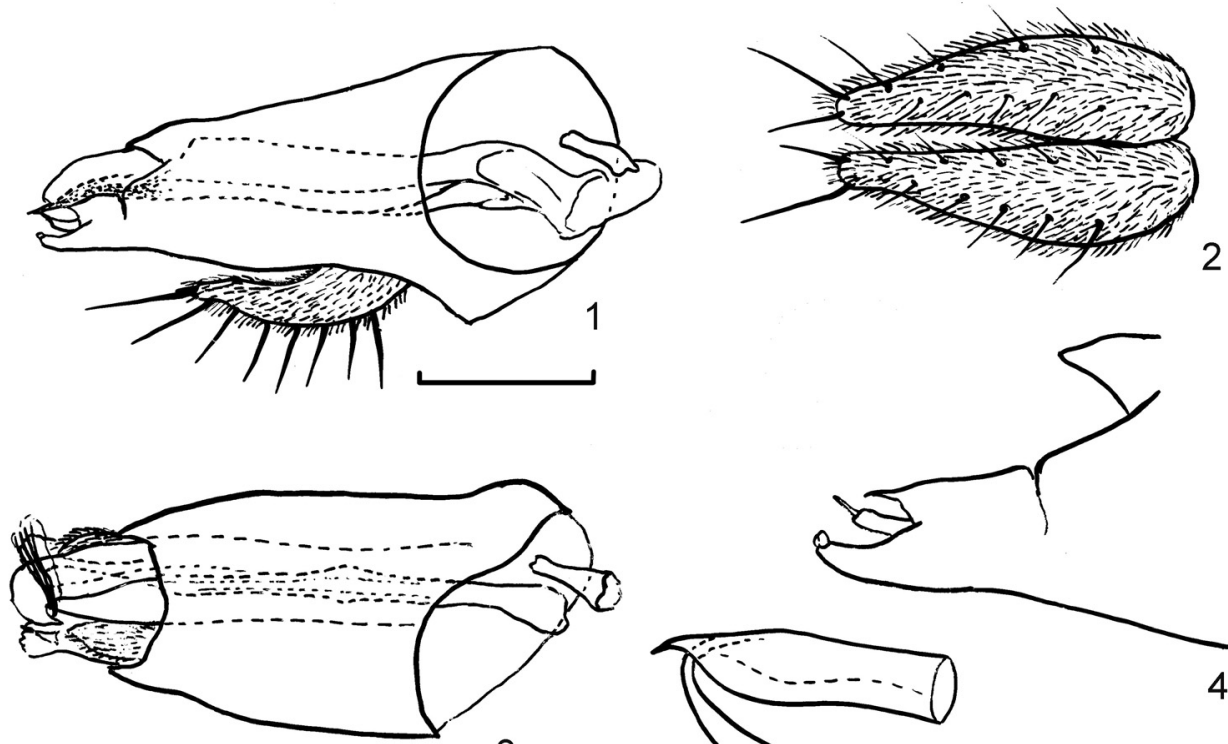

3
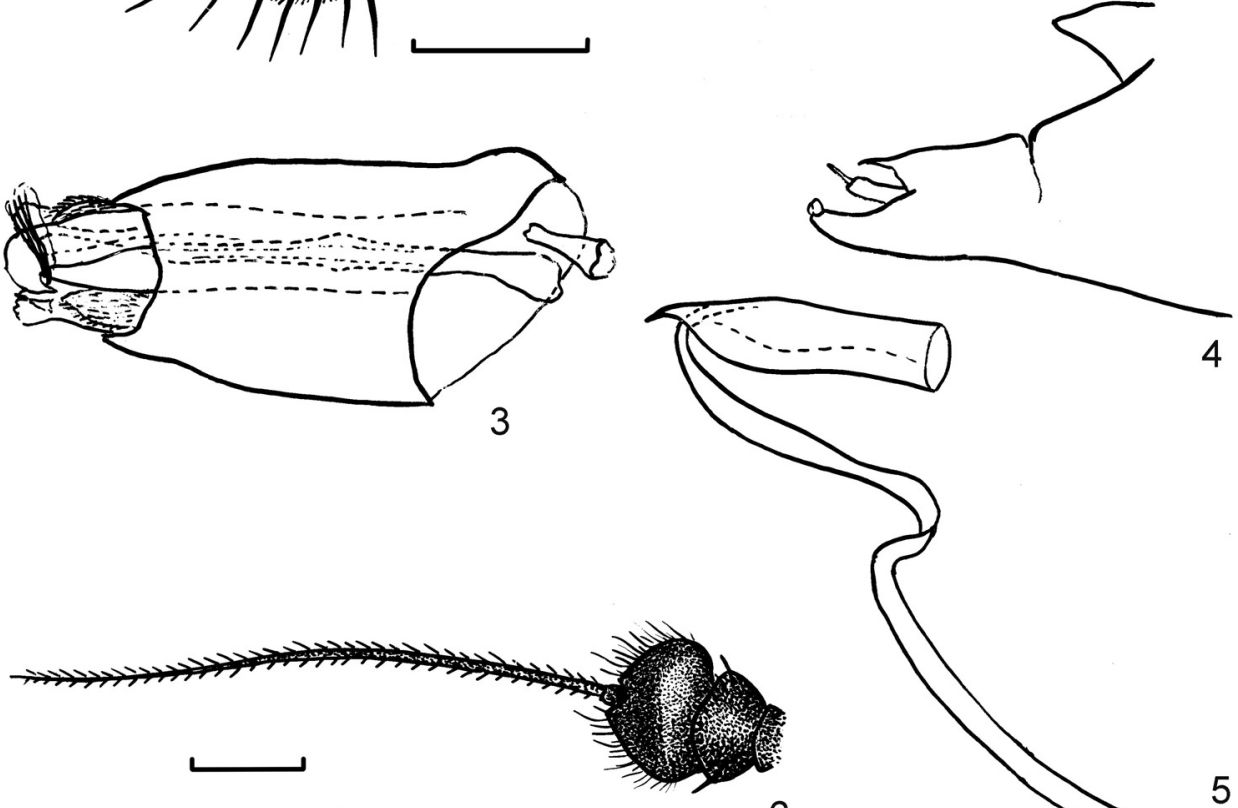

6

Figs 1-5. Thinophilus (Schoenophilus) grootaerti, sp. n.: $1=$ hypopygium, lateral, $2=$ cerci, dorsal, $3=$ hypopygium, ventral, $4=$ sursyli, lateral, $5=$ phallus, lateral, $6=$ antennae. Scales:

$0.1 \mathrm{~mm}$. 
hairs. Fore femora and tibia without long setae. Fore tibia with 2 short setae at apex. 1st segment of fore tarsi not curved, with short ventral hairs. Ratio of fore tibia and tarsus (from 1st to 5th): 3.3/1.4/0.7/0.5/0.4/0.5. Mid and hind femora without long setae. Mid tibia with 2 short anterodorsal setae and 3 long setae at apex. Ratio of mid tibia and tarsus (from 1 st to 5 th): 4.2/2.4/1.2/0.7/0.4/0.5. Hind coxa with 1 short seta. Hind tibia with 2 anterodorsal and 2 posterodorsal setae, with 2 setae at apex. 1st segment of hind tarsi without long setae. Ratio of hind tibia and tarsus (from 1st to 5th): 4.9/1.4/1.4/0.7/0.5/0.6.

Wing darkened. $\mathrm{R}_{4+5}$ and $\mathrm{M}_{1+2}$ parallel apically. $\mathrm{M}_{1+2}$ slightly curved. Ratio of costal section between $R_{2+3}$ and $R_{4+5}$ to that between $R_{4+5}$ and $M_{1+2}: 1.4 / 0.9$. Apical part of $M_{3+4}$ longer than $\mathrm{m}-\mathrm{cu}-1.3 / 0.8$. Anal angle obtuse. Lower calypter with white hairs. Halter yellow.

Abdomen metallic green, with bronze tingle and dense grey polliposity, with black hairs. Epandrium narrow, long, widened at base, with angle-shape process on dorsal side at base, longer than wide. Surstylus longer than cerci, with deep incisure and two processes. Cerci elongated oval, rounded at apex, with setae and dense hairs.

Female. Similar to male except: face broader.

Length: body $1.3-1.4 \mathrm{~mm}$, wing $1.3-1.4 \mathrm{~mm}$.

Type material. Holotype. $\$$, Maritime Territory, the natural state reserve "Kedovaja Padj “, 21.07.1981 (Negrobov). Paratypes: $1 \delta, 2$, in the same place. Types are stored in the Zoological Institute of the Russian Academy of Sciences, two paratypes are stored in the collection of the Voronezh University.

Etymology. The new species is named after my friend, famous dipterologist from Belgium Dr. Patrick Grootaert.

Differential diagnosis. The new species can be distinguished from the single Palaearctic species in the subgenus Schoenophilus by following characters:

- Wings without spots. Palpus yellow. Fore coxa and femora yellow. Halter yellow. Surstylus with two processes at apex

\section{Thinophilus (Schoenophilus) grootaerti sp. n.}

- Wings with dark spots on $\mathrm{m}-\mathrm{cu}$ and on curvature of $\mathrm{M}_{1+2}$. Palpus browngrey. Fore coxa and femora brown-yellow. Halter brown-yellow. Surstylus with one process at apex Thinophilus (Schoenophilus) versutus Haliday

This subgenus is recorded for the first time from Asia, the Maritime Territory.

\section{Thinophilus ovtshinnikovae sp. n.}

(Figs 7-8)

Diagnosis. Frons with grey pollinosity. Face with grey pollinosity. Antennae black. Arista subapical. Palpus light-yellow with black hairs. Mesonotum without black spot. 5 pairs of dorsocentral setae. Scutellum with 4 lateral setae. Legs yellow. Fore coxa with white hairs. 1st segments of fore tibia not curved. Segments of tarsus not widened. Hind femora with short anteroventral hairs. 
Description. Male. Frons green with grey pollinosity. Face green with grey polliposity, width at suture is equal to the width of postpedicel. Antennae black, arista black. Ratio of epistome length, clypeus length, face width at suture and palpus length: 0.8/0.5/0.3/0.5. Arista subapical, shortly pubescent. Postpedicel transversely oval with rounded apex, wider than long. Ratio of postpedicel length to width and arista length: 0.4/0.5/2.0. Pedicel without process, projecting on postpedicel. Proboscis brown. Palpus short, light-yellow with black hairs. Postocular setae white below.

Thorax green. Mesonotum with grey pollinosity, with two lighter longitudinal strip, pleura with dense grey pollinosity, without purple spot. Propleuron with 1-2 short white hairs. Mesonotum without black spot. Acrostichal setae absent. 5 pairs dorsocentral setae. Scutellum with 4 lateral setae.

Legs yellow, most of mid and hind coxa brown, tibia darkened at apex. Fore coxa with white hairs. Fore femora and tibia without long setae. 1st segments of fore tibia not curved, without crest of erect setae. Segments of tarsus not widened, without setae. Ratio of fore tibia and tarsus (from 1st to 5th): 3.1/1.7/0.6/0.5/0.3/0.3. Mid femora with short preapical hairs, without long hairs below. Mid tibia with 2 short anterodorsal setae and 1 posterodorsal seta. Segments of mid tarsi without long setae. 5th segment of mid tarsi widened. Ratio of mid tibia and tarsus (from 1st to 5th): 4.1/2.2/0.9/0.7/0.4/0.4. Hind femora with short anteroventral hairs in upper third. Hind tibia with very short setae on dorsal side. Segments of hind tarsi without setae. Ratio of hind tibia and tarsus (from 1st to 5th): 4.3/1.9/1.0/0.7/0.4/0.3.

Wing darkened. $\mathrm{R}_{4+5}$ and $\mathrm{M}_{1+2}$ slightly divergent apically. $\mathrm{M}_{1+2}$ slightly curved. Ratio of costal section between $R_{2+3}$ and $R_{4+5}$ to that between $R_{4+5}$ and $M_{1+2}: 1.4 / 0.9$. Apical part of $\mathrm{M}_{3+4}$ longer than $\mathrm{m}-\mathrm{cu}-1.0 / 0.7$. Anal angle obtuse. Lower calypter yellow with white hairs. Halter yellow.

Abdomen metallic green, with bronze strips laterally, with black hairs, with grey pollinosity. Epandrium narrow, narrowed at apex. Surstylus shorter than cerci. Phallus annular curved.

Female. Similar to male except: face broader.

Length: body $1.3 \mathrm{~mm}$, wing $1.3 \mathrm{~mm}$.

Type material. Holotype. $\hat{\sigma}$, China, $50 \mathrm{~km}$ north of Mukden, 20.07.1952 (Rubtsov), Paratypes: $1 \hat{\delta}, 2$, in the same place. Types are deposited in the Zoological Institute of the Russian Academy of Sciences.

Etymology. The new species is named after famous specialist in Diptera of the Zoological Institute of the Russian Academy of Sciences Olga G. Ovtshinnikova.

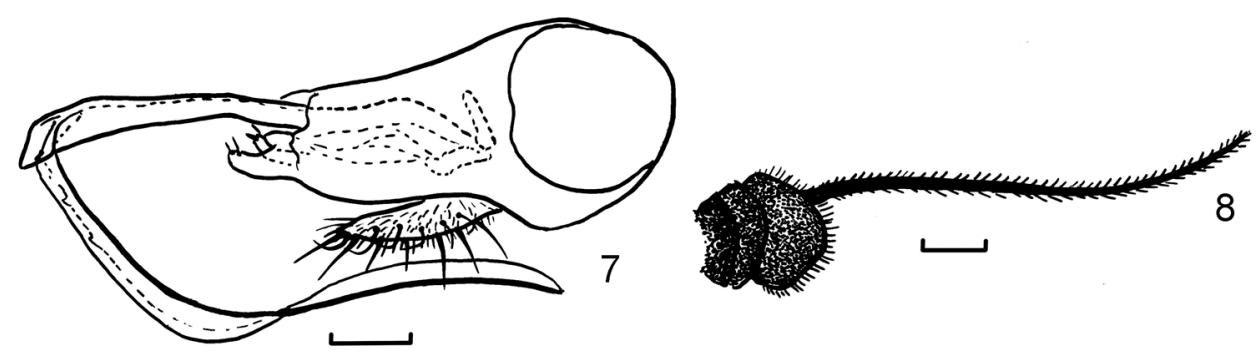

Figs 7-8. Thinophilus ovtshinnikovae Negrobov, Maslova et Selivanova, sp. n.: 7 = hypopygium, lateral, $8=$ antennae. Scales: $0.1 \mathrm{~mm}$ for Fig. 7, $0.5 \mathrm{~mm}$ for Fig. 8. 
Differential diagnosis. In the key to Palaearctic species (Negrobov 1971, 1979), the new species runs to Thinophilus ruficornis (Haliday, 1838) and can be distinguished from the latter by following characters:

- Antennae black. Dorsal part of epandrium with deep incisures. Surstylus slightly longer than wide. Phallus long curved, longer than epandrium

Thinophilus ovtshinnikovae sp. $\mathrm{n}$.

- Antennae mostly yellow. Dorsal part of epandrium almost straight. Surstylus 2 times longer than wide. Phallus short, shorter than epandrium

Thinophilus ruficornis (Haliday, 1838)

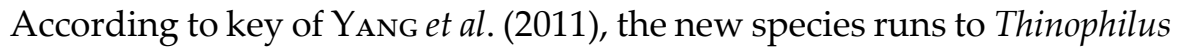
seticoxis Becker, 1922, are known from Oriental region of China (Taiwan) and Indonesia and can be distinguished from it by following characteristics:

- Antennae black. Femora without setae below. Thorax and abdomen green

Thinophilus ovtshinnikovae $\mathrm{sp}$. $\mathrm{n}$.

- Antennae mostly yellow. Femora with setae below. Thorax and abdomen partly purple

Thinophilus seticoxis Becker, 1922

Thinophilus seticoxis Becker, 1922

Thinophilus seticoxis Becker, 1922, Capita zool. (Den Haag) 1(4): 36.

Syntypes Thinophilus seticoxis stored in Museum für Naturkunde Humboldt-Universität zu Berlin. Lectotype: $\delta$, Kankau (Formosa), IX, 12 (Sauter) (by present designation). Paralectotype: 2 , Tainan, Formosa, 11.09 (Sauter).

A KEY TO THINOPHILUS MALES

OF THE EASTERN PALAEARCTIC

1. 4 pairs of dorsocentral setae. Arista apical

T. (Schoenophilus) grootaerti sp. n.

- 5-6 pairs of dorsocentral setae. Arista dorsal

2. Mesonotum with brown spot on $\mathrm{M}_{1+2}$ and m-cu 3

- Mesonotum without black spot 4

3. Wing with brown spots

T. indigenus Becker, 1902

- Wing without spots

T. sinensis Yang et $\mathrm{Li}, 1998$

4. Scutellum with 2 lateral setae

T. argyropalpis Becker, 1907 
- Scutellum with 4 setae $\quad 5$

5. 1st segment of fore tarsi sharply curved 6

- 1 1st segment not curved $\quad 7$

6. 2nd-4th segments of fore tarsi with group of long black setae

T. flavipalpis (Zetterstedt, 1843)

- $\quad$ 2nd-4th segments of fore tarsi without long setae

T. spinitarsis Becker, 1907

7. Femur in most part black T. setosus Negrobov, 1979

- Femora yellow 8

8. Mid femora with long hairs bellow, which length exceed of femora diameter T. longipilus Negrobov, 1971

- Mid femora with short hairs bellow

9. Antennae black

T. ovtshinnikovae sp. n.

- Antennae partly yellow

10. Fore coxa dark. Wing without spots T. nigripenis Negrobov, Kumazawa et Tago, 2014

- Fore coxa yellow. Wing which two spots: on curvature of $\mathrm{M}_{1+2}$ and $\mathrm{m}$-cu

11. 1st segment of fore tarsi with long ventral setae T. pollinosus Loew, 1871

- $\quad 1$ st segment of fore tarsi with short ventral setae

T. ruficornis (Haliday, 1838)

\section{NEW DATA}

Thinophilus argyropalpis Beck. -1 , , Mongolia, Chovd aimak, Jamatin Dolon, ca. $40 \mathrm{~km}$ N von Somon Manchan, an der SW Ecke des Sees Char us nuur, $1200 \mathrm{~m}, 11$. VII. 1966 (Nr. 673), leg. Z. Kaszab. Distribution: South Europe, Asia Minor, Middle Asia, North Africa. Russia: Volgograd region.

Thinophilus flavipalpis (Zett.) - 1 , , Mongolia, Cojbalsan aimak, Somon Tamzagbulag, 600 m, 10. VIII. 1965 (Nr. 388), leg. Z. Kaszab. Distribution: North Africa, Europe, Asia Minor, China.

Thinophilus pollinosus Loew, 1871 - Syntypes stored in Museum für Naturkunde Humboldt-Universität zu Berlin. Lectotype: 1 స, Tadjikistan, Zeravschar Thal, № 12695, (Fedschenko); Paratype: $1 \hat{\delta}$, in the same place (by present designation).

Material: 1 क, Mongolia, Central aimak, 125 km SW of Ulan-Bator, 30-31.07.1969 (Kerzhner), 2 o, 1 ㅇ, Mongolia, South Gobi aimak, $10 \mathrm{~km}$ NO of Mountain Onch- 
Khairkhan-ula, 08.04.1967 (Kerzhner), 2 ऽ, Mongolia, South Gobi aimak, $30 \mathrm{~km}$ SSO of Sugin-khuduk, 03.08.1967 (Kerzhner), 1 ㅇ, Mongolia, Bayan-Khongor aimak, the north shore of Lake Orog-nur, 15-16.08.1967 (Emelyanov), 3 o, Mongolia, Bayan-Khongor aimak, the north shore of Lake Orog-nur, 15-16.08.1967 (Zaitsev), 1 $\hat{\varnothing}$, Mongolia, Bayan-Khongor aimak, the north shore of Lake Orog-nur, 15-16.08.1967 (Kerzhner), 1 d , 1 \&, Mongolia, Bayan-Khongor aimak, Toroin-Bulak, $13 \mathrm{~km}$ O of Tsagan-Bulak, 16.08.1969 (Kerzhner), 1 d., Mongolia, Bayan-Khongor aimak, oasis Ehin-Gol, 11-14.08.1969 (Kerzhner), 3 ô, 6 , Mongolia, Upper-Gobi aimak, Barun-bayan, 20 km OSO of Tal-Hongoryn-Khuduk, 2930.06.1971 (Kerzhner), 1 을 Mongolia, Sukhe-Bator aimak, sands of Orgon-Els, 15 km SSO of Khongor, 5-6.07.1971 (Kozlov), 1 $\hat{\jmath}^{2}$, Mongolia, Sukhe-bator aimak, Avdartyn-Khuduk $35 \mathrm{~km}$ WNW of Dzotol-Khan, 07.13.1971 (Kerzhner), 10 o, 16 , the southern part of Mongolia, the Valley of Lakes, in the foothills of the Gobi-Altai, the north shore of Lake OrogNuur, 16-18.08.1967 (Emelyanov, Kozlov), 1 o, 2 우, Mongolia, Sudgobi aimak, Nojon nuruu, Grenzposten Ovot Chuural, 1500 m, 21.06.1967, Nr. 829, Exp. Dr. Z. Kaszab, 1 , Russia, Omsk reg., Severnaya, shore of lake Solodovoe, 23.07.1922 (Reichard), 1 ¿ , Russia, Transbaikalica, Republic Buryatia, Kyakhta district, Troitskosavsk (town, which became part of the city Kyakhta in Buryatia), 27.06. 1928 (Lukyanovich), 4 ऽ, 6 , , Russia, Trasbaicalia,18.07.1928. (Lukjanovitsh).

This species was noted by Loew (1871) from Russia within the old boundaries, it is an indication of the territory of modern Tajikistan. The species are known from Crimea (Grichanov et al. 2012), Ukraine (Negrobov 1971, 1980), Mongolia (Negrobov 1973a, 1974), Azerbaijan (Grichanov \& Tомкоvich 2009), China (Yang et al. 2011). The species are noted for the first time from Russia.

Thinophilus ruficornis (Hal.) - 1 , Mongolia, Suchebaator aimak: Fluss Bajan gol, 85 km NO von Somon Dariganga, 1100 m, 8. VIII. 1965 (Nr. 377), 1 ㅇ, Mongolia, Chovd aimak: 10 km NW von Somon Uenc, 1480 m, 4. VII. 1966 (Nr. 625), leg. Z. Kaszab. Distribution: Azerbaijan (Grichanov \& Toмкоvich 2009), Ukraine (Negrobov 1971, 1980), Mongolia (Negrobov 1973, 1974), Russia: Murmansk and Orenburg regions, Yakutia, North Caucasus, Crimea (Grichanov et al. 2012).

Acknowledgements - The work was supported by the Russian Foundation for Basic Research, grant number 14-04-00264.

\section{REFERENCES}

Grichanov, I. Ya., Negrobov, O. P., Przhiboro, A. A. \& Ovsyannikova, E. I. (2012) On the Dolichopodidae fauna of Crimea (Diptera). Cesa News 82: 1-13.

Grichanov, I. YA. \& Toмкоvich, K. P. (2009) New data on the distribution of Dolichopodidae (Diptera) in Azerbaijan. International Journal of Dipterological Research 20(2): 99-110.

Grootaert, P. \& Meuffels, H. S. G. (1984) Dolichopodidae (Diptera) from Papua New Guinea II. Some new species of the genus Thinophilus Wahlberg, 1844 from the Lowland. Indo-Malayan Zoology 2: 209-223.

Harrison, R. A. (1964) Insects of Campbell Island. Diptera. Pacific Insects Monographs 7: 304-324. 
LAмв, C. G. (1909) Article VII. The Diptera of the subantarctic islands of New Zealand. Pp. 124-145. In: Chilton, C. (ed.): The subantarctic islands of New Zealand. Reports on the geo-physics, geology, zoology and botany of the islands lying to the south of New Zealand, based mainly on observations and collections made during an expedition in the government steamer "Hinemoa" (Captain J. Bollons) in November, 1907. Vol. 1. Philosophical Institute of Canterbury, Christchurch.

Loew, H. (1871) Turkestanskie dvukrylye [Turkestan Diptera]. Izvestia imperatorskogo obshestvava ljubitelej estestvoznania, antropoljgii i etnografija. M. 9: 52-59. [in Russian]

Negroвov, O. P. (1971) Revizija palearkticheskikh vidov dvukrylykh roda Thinophilus (Diptera, Dolichopodidae) [Revision of Palaearctic species of Diptera of the genus Thinophilus (Diptera, Dolichopodidae)]. Entomologicheskoe Obozrenie 50(4): 896-910. [in Russian]

Negrobov, O. P. (1973) Die Dolichopodiden-Arten (Diptera) aus der Mongolischen Volksrepublik, 2. Acta Zoologica Academiae Scientiarum Hungaricae 19(2): 133-153.

Negrobov, O. P. (1974) K faune Dolichopodidae (Diptera) Mongolskoi narodnoi respubliki [The fauna of Dolichopodidae (Diptera) of the Mongolian People's Republic]. Nasekomye Mongolii. Leningard. Nauka. Vyp. 2: 335-346. [in Russian]

Negrobov, O. P. (1976) Novye vidy Dolichopodidae (Diptera) iz Mongolskoi narodnoi Respubliki [New species of the Mongolian People's Republic]. Nasekomye Mongolii. Leningard., Nauka. Vyp. 4: 501-508. [in Russian]

Negrobov, O. P. (1979) Dolichopodidae. Hydrophorinae. In: Lindner, E. (ed.): Die Fliegen der Palaearktischen Region. Stuttgart. V.29. Lf. 321: 419-474.

Negrobov, O. P. \& Grichanov, I. Ya. (1982) Novye vidy dvukrylyh semejstva Dolichopodidae (Diptera) iz Tadzhikistana i Kirgizii [New species of Diptera of family Dolichopodidae (Diptera) from Tajikistan and Kyrgyzstan]. Novye vidy nasekomyh Srednej Azii, Leningrad, Nauka. pp. 105-108. [in Russian]

Negrobov, O. P., Kumazawa, T., Tago, T. \& Maslova, O. O. (2014) The species of the genus Thinophilus Loew, 1864 (Dolichopodidae, Diptera) of Japan. Far Eastern Entomologist 281: 1-6.

YANG, D. \& LI, Z. (1998) Diptera: Dolichopodidae. In: Wu, H. (ed.): Insects of Longwangshan Nature Reserve. China Forestry Publishing House, Beijing. 404: 318-323. [in Chinese]

YANG, D., Zhang, L., Wang, M. \& Zhu, Y. (2011) Dolichopodidae. Fauna Sinica, Insecta 53. Science Press, Beijing, 1912 pp.

Received June 22, 2015, accepted September 25, 2015, published May 6, 2016 


\title{
Contributions to a Manual of Palaearctic Diptera
}

\author{
Edited by L. Papp and B. Darvas \\ Volumes 1-3, Appendix
}

The excellently illustrated volumes of the "Contributions to a Manual of Palaearctic Diptera" morphological, physiological, genetical, ecological and economic up-to-date knowledge of dipterous species (midges and flies), which have significant importance in genetics as model organisms, in plant cultivation as pests or beneficial parasitoids, in animal husbandry and human health as vectors of serious illnesses and which are important for ecosystem function, are treated. Morphological keys to generic level for adults and larvae are provided, which help readers with identification of dipterous pests and parasitoids, while readers in the field of applied dipterology will find suitable environmentally friendly methods against pests or biological control methods.

Volume 1 (published in 2000): 24 chapters of general and applied dipterology, by 31 specialists, on 978 pages with 956 figures on 176 plates. Volume 2 (published in 1997): 38 dipterous family chapters, by 23 specialists, on 592 pages with 1895 figures on 258 plates. Volume 3 (published in 1998): 56 dipterous family chapters, by 32 specialists, on 880 pages with 1773 figures on 294 plates. Appendix (published in 2000): 16 dipterous family chapters, by 19 specialists, on 604 pages with 2134 figures on 207 plates.

ISBN 9630488361 (Series)
ISBN 9630488396 (Volume 1)
ISBN 963048837 X (Volume 2)
ISBN 963048838 (Volume 3)
ISBN 963048840 X (Appendix)

Foundation for the Publicity of the Hungarian Science

Publisher: Science Herald, Budapest

Order should be sent to

NEST Foundation, Collegium Budapest

Ms Szilvia Zimber, E-mail: szimber@ colbud.hu 